\title{
Inhibition of Lipolysis by Adenosine Is Potentiated with Age
}

\author{
Brian B. Hoffman, Helen Chang, Zohreh Farahbakhsh, \\ and Gerald Reaven \\ Geriatric Research, Education and Clinical Center, Veterans \\ Administration Medical Center, Palo Alto, California 94304; \\ Department of Medicine, Stanford University Medical School, \\ California 94305
}

bstract. The ability of a variety of hormones to activate cells declines with age. We have investigated the mechanism for the reduced ability of beta adrenergic stimulation to activate lipolysis in fat cells from older rats. Previously, we have found that these cells have an intact lipolytic response to a cAMP analogue but diminished cAMP accumulation after isoproterenol stimulation, suggesting that the blunted cAMP response is rate limiting. In the present study we have tested the hypothesis that enhanced inhibition of lipolysis by endogenously released adenosine accounts for the diminished lipolysis.

Adenosine deaminase was added to media containing the adipocytes from older rats to remove endogenous adenosine. Under these conditions beta adrenergic stimulation of lipolysis is intact in fat cells from older rats. The adenosine analogue $N^{6}$-phenylisopropyladenosine more effectively inhibited lipolysis in the older group $(77 \pm 6 \%)$ than in the younger group $(46 \pm 5 \%)$, suggesting that enhanced efficacy of endogenous adenosine may account for the reduced lipolytic response to catecholamines. When pertussis vaccine was used to functionally inactivate adenosine receptors in adipocytes from the younger and older rats, the ability of isoproterenol to activate lipolysis was restored in the older group. All the data are consistent with the hypothesis that enhanced inhibitory effects of adenosine explain the diminished ability of beta adrenergic agonists to activate lipolysis. It is possible that enhanced inhibitory pathways may be involved in blunting responses to stimulatory hormones in other tissues from older animals.

Address reprint requests to Dr. Hoffman, VA Medical Center (182B), 3801 Miranda Avenue, Palo Alto, CA 94304.

Received for publication 30 April 1984 and in revised form $16 \mathrm{July}$ 1984.

J. Clin. Invest.

(c) The American Society for Clinical Investigation, Inc.

$0021-9738 / 84 / 11 / 1750 / 06 \$ 1.00$

Volume 74, November 1984, 1750-1755

\section{Introduction}

Responsiveness to a variety of hormones declines with age in a wide range of tissues. With aging, the action of catecholamines at beta adrenergic receptors has been found to be diminished in a number of target organs such as the heart and the peripheral circulation (1-3). Much interest has focused on adipocytes isolated from aged rats as a model system to study this blunted responsiveness. It is generally agreed that activation of lipolysis by beta adrenergic agonists is reduced as rats grow older, although the mechanism responsible for this change is unclear (4-7). Catecholamines activate lipolysis in rat fat cells by interacting with beta receptors, which stimulate cAMP production; cAMP activates a protein kinase that ultimately stimulates triglyceride lipase leading to lipolysis. Presumably, developmental and age-related changes in responsiveness to catecholamines involve alteration(s) in these pathways.

We have recently found that the beta adrenergic agonist isoproterenol is less effective in maximally activating lipolysis in adipocytes from 12-mo-old compared with 2-mo-old rats (7a). However, a cAMP analogue that directly activates cAMPdependent protein kinase was equally effective in the two groups. This suggested that the deficit in responsiveness to isoproterenol was actually caused by the diminished cAMP accumulation that was also observed in the adipocytes from the older rats. The explanation for the blunted cAMP response to isoproterenol was unclear in those studies, although we showed that there was no loss in the beta adrenergic receptors from the adipocytes of the older rats. Furthermore, there was no difference in phosphodiesterase activity between the two groups (7a). The present experiments were designed to further explore the mechanism for the blunted response to beta adrenergic stimulation.

Adenosine is an antilipolytic substance that is released from adipose tissue and accumulates in the incubation buffer when isolated fat cells are incubated in vitro (8-10). The adenosine released from adipocytes may inhibit lipolysis by interacting with specific adenosine receptors on the fat cells, and in this study we have tested the possibility that the blunted response to isoproterenol of fat cells from older rats could be a result of an increased inhibition of lipolysis mediated by adenosine. Our results are consistent with this hypothesis, and 


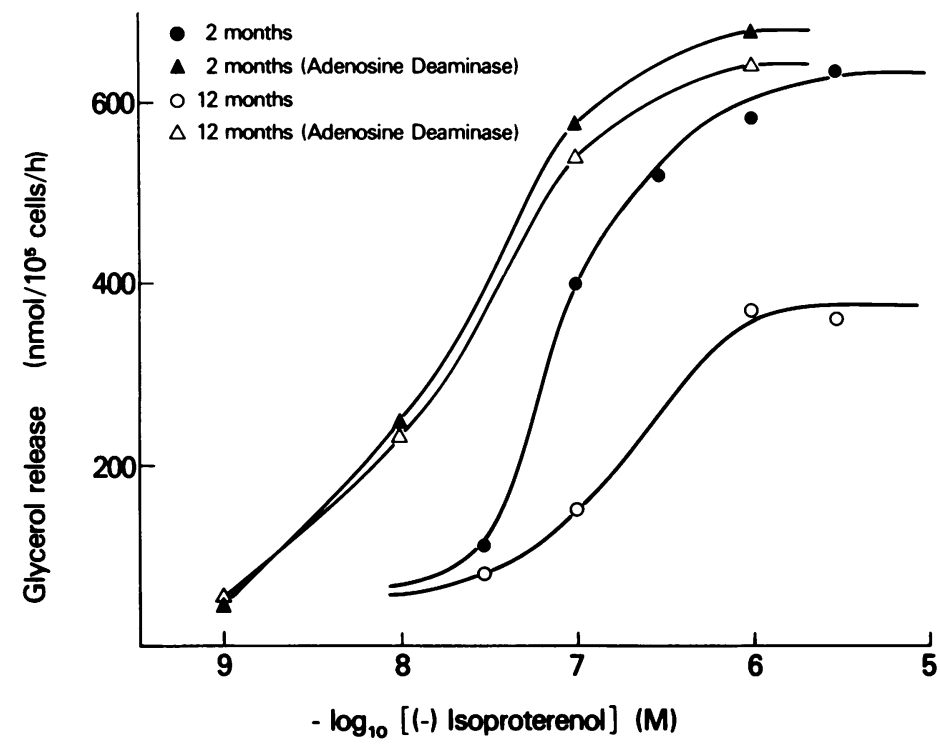

Figure 1. Stimulation of lipolysis by isoproterenol in the presence and absence of adenosine deaminase. Fat cells were isolated from young or older rats as described in Methods. The cells from each group were divided into two sets, which were incubated with various concentrations of isoproterenol in the presence or absence of a fixed concentration of adenosine deaminase $(1 \mathrm{U} / \mathrm{ml})$. Glycerol release was determined as indicated in Methods. This representative experiment was repeated five times. they suggest that the increased effectiveness of locally released adenosine is responsible for the reduced beta adrenergic stimulation of lipolysis with age.

\section{Methods}

Chemicals were obtained from the following sources: collagenase (Worthington Biochemicals, Freehold, NJ); (-)isoproterenol (+)bitartrate and adenosine deaminase (Sigma Chemical Co., St. Louis, MO); $(-) N^{6}$-phenylisopropyladenosine (Boehringer Mannheim Biochemicals, Indianapolis, IN); $\left[{ }^{3} \mathrm{H}\right] N^{6}$-phenylisopropyladenosine (Amersham Corp., Arlington Heights, IL). All other chemicals were obtained from the standard commercial sources. Pertussis vaccine was a kind gift from Lederle Laboratories, Pearl River, NY.

Preparation of isolated fat cells. Male 6-8-wk-old and 12-mo-old Sprague-Dawley rats were used. The rats were fed standard laboratory chow ad lib. and maintained on a 12-h light-dark ( 0600 hours/1,800 hours) cycle. The rats were killed by decapitation at 10:00 AM. Fat cells were prepared from epididymal fat pads according to the method of Rodbell (11) with minor modification. The fat pads were minced with scissors and placed in plastic flasks in Krebs-bicarbonate buffer with $4 \%$ bovine serum albumin, $3 \mathrm{mM}$ glucose, and $3 \mathrm{mg}$ collagenase/ $\mathrm{ml}$. Collagenase digestion was carried out at $37^{\circ} \mathrm{C}$ in a gyratory water bath shaker for $60 \mathrm{~min}$. Cells were washed three times in fresh Krebs$4 \%$ albumin- $2.5 \mathrm{mM}$ glucose buffer and allowed to separate from the infranatant by floatation. A $500-\mu \mathrm{l}$ aliquot of diluted cells was fixed in a solution of $2 \%$ osmium tetra oxide in collidine buffer and was counted in a Coulter counter (Coulter Electronics Inc., Hialeak, FL) to determine the cell number.

Lipolysis. Fat cells were diluted in Krebs-4\% albumin- $2.5 \mathrm{mM}$ glucose buffer, $\mathrm{pH}$ 7.4. Aliquots of diluted cells were placed into plastic vials $\left(\sim 1 \times 10^{5}\right.$ cells $\left./ \mathrm{ml}\right)$. Drugs were added to the cells and incubated at $37^{\circ} \mathrm{C}$ for $1 \mathrm{~h}$ in an atmosphere of $\mathrm{O}_{2}(95 \%), \mathrm{CO}_{2}(5 \%)$. At the end of incubation, an aliquot $(0.2 \mathrm{ml})$ of infranatant was removed from each incubation mixture for measurement of lipolysis. The rate of lipolysis is expressed as glycerol release; glycerol was measured by the enzymatic method described by Wieland (12).
Measurement of adenosine receptors. Isolated adipocytes were prepared and counted as described above. The isolated adipocytes were lysed by homogenization in buffer $(0.25 \mathrm{M}$ sucrose, $10 \mathrm{mM}$ Tris $\mathrm{HCl}$, and $1 \mathrm{mM}$ EDTA, pH 7.4) and centrifuged at $20,000 \mathrm{~g}$ for $20 \mathrm{~min}$. The pellet was resuspended in $50 \mathrm{mM}$ Tris- $\mathrm{HCl}, 1 \mathrm{mM} \mathrm{MgCl}_{2}, \mathrm{pH}$ 7.4. Adenosine receptors in these membranes were labeled with $N^{6}$ $\left[{ }^{3} \mathrm{H}\right]$ phenylisopropyladenosine as described by Trost and Schwabe (13). Briefly, fat cell membranes $(80-120 \mu \mathrm{g}$ protein $/ 100 \mu \mathrm{l})$ were incubated with adenosine deaminase $(0.25 \mathrm{U} / \mathrm{ml})$ for $10 \mathrm{~min}$ at $30^{\circ} \mathrm{C}$. The membranes were then used immediately or stored frozen at $-70^{\circ} \mathrm{C}$ and used within 1 wk without loss of binding sites. Adenosine deaminase-treated fat cell membranes were incubated with varying concentrations of $N^{6}-\left[{ }^{3} \mathrm{H}\right]$ phenylisopropyladenosine $(3-20 \mathrm{nM})$ at $37^{\circ} \mathrm{C}$ for $30 \mathrm{~min}$ as described (13). Unlabeled $N^{6}$-phenylisopropyladenosine $(100 \mu \mathrm{M})$ was used to define nonspecific binding. Data from the saturation curves were analyzed using a nonlinear least squares fitting program run on a HP 9816 computer (Hewlett Packard Co., Palo Alto, CA).

\section{Results}

To test the hypothesis that adenosine was responsible for the blunted response to isoproterenol with age, adipocytes were isolated from 2-mo and 12-mo-old rats. The ability of isoproterenol to stimulate lipolysis in these cells is illustrated in Fig. 1. As we have found previously, the maximal response to isoproterenol is less in adipocytes from the older rats. Also, isoproterenol's effective concentration ${ }_{50}\left(\mathrm{EC}_{50}\right)^{1}$ in adipocytes from older rats was significantly increased indicating a loss in sensitivity (Table I). Dose-response curves with isoproterenol were also constructed from the same population of adipocytes

1. Abbreviation used in this paper: $\mathrm{EC}_{50}$, effective concentration ${ }_{50} ; \mathrm{Ni}$, inhibitory regulatory protein. 
Table I. Activation of Lipolysis by Isoproterenol

\begin{tabular}{lll}
\hline & $\begin{array}{l}\text { Maximal glycerol } \\
\text { release }\end{array}$ & $\mathrm{EC}_{\text {so }}(\mathrm{M})$ \\
\hline & $\begin{array}{l}n m o l / 10^{5} \text { cells } \\
\text { per } h\end{array}$ & \\
Control & & \\
$\begin{array}{c}\text { Adipocytes from } \\
\text { 2-mo-old rats }\end{array}$ & $571 \pm 44$ & $5.6 \pm 0.6 \times 10^{-8}$ \\
$\begin{array}{c}\text { Adipocytes from } \\
\text { 12-mo-old rats }\end{array}$ & $410 \pm 21^{*}$ & $1.1 \pm 0.1 \times 10^{-7 *}$ \\
$\begin{array}{l}\text { In the presence of adenosine } \\
\text { deaminase }\end{array}$ & & \\
$\begin{array}{c}\text { Adipocytes from } \\
\text { 2-mo-old rats }\end{array}$ & & \\
$\begin{array}{c}\text { Adipocytes from } \\
\text { 12-mo-old rats }\end{array}$ & $687 \pm 58$ & $9.4 \pm 2.6 \times 10^{-9} \ddagger$ \\
\hline
\end{tabular}

Glycerol release was measured as described in Methods. The data represent the mean \pm SEM of six experiments.

* Different from 2-mo-old rats, $P<0.02$.

¥Different from corresponding value in the absence of adenosine deaminase, $P<0.001$.

$\S$ Different from corresponding value in the absence of adenosine deaminase, $P<0.01$ and not significantly different from value in 2 -moold rats in presence of adenosine deaminase.

in the presence of adenosine deaminase $(1 \mathrm{U} / \mathrm{ml})$. Adenosine deaminase has been used in experiments with isolated adipocytes to convert the spontaneously liberated adenosine to inosine, which does not inhibit lipolysis $(8,9)$. In the presence of adenosine deaminase, the response to isoproterenol was equivalent in the younger and older rats (Fig. 1 and Table I).
Not only was the maximal response restored in the adipocytes from the older rats but also isoproterenol's $\mathrm{EC}_{50}$ was not significantly different when compared with the adipocytes from the younger rats.

These observations suggested that adenosine played a role in blunting the response to isoproterenol with age. There appeared to be two major alternatives to explain the effect of adenosine; namely, that adenosine was able to inhibit lipolysis more effectively in fat cells from the older rats or that these cells released more adenosine. In an effort to distinguish between these possible alterations, experiments were conducted using the adenosine analogue, $N^{6}$-phenylisopropyladenosine. This compound interacts with adenosine receptors to inhibit lipolysis but is not itself a substrate for the enzyme adenosine deaminase (9). The ability of $N^{6}$-phenylisopropyladenosine to inhibit maximal isoproterenol stimulated lipolysis in the presence of adenosine deaminase is shown in Fig. 2. The maximal inhibition of lipolysis was significantly greater in the adipocytes for the older rats $(77 \pm 6 \%)$ compared with the younger rats (46 $\pm 5 \%), P<0.001, n=6$. There was no significant difference in the drug's $\mathrm{EC}_{50}$ between the older $\left(7.1 \pm 1.4 \times 10^{-10} \mathrm{M}\right)$ and younger $\left(09.9 \pm 50 \times 10^{-10} \mathrm{M}\right)$ rats. These data suggest that adenosine has a larger maximal effect on inhibition of lipolysis in cells from older rats. Similarly, the adenosine receptor antagonist isobutylmethylxanthine reversed the deficit found in the older rats (data not shown).

The possibility that adenosine-mediated inhibition of lipolysis played an important modulating role in the cells from the older rats was evaluated using pertussis vaccine. Pertussis vaccine contains the protein pertussis toxin, which reduces the ability of certain hormone receptors to inhibit adenylate cyclase in a variety of cells, including adipocytes $(14,15)$. The mechanism by which this occurs is thought to involve the ADPribosylation of inhibitory regulatory protein $(\mathrm{Ni})$, which me-

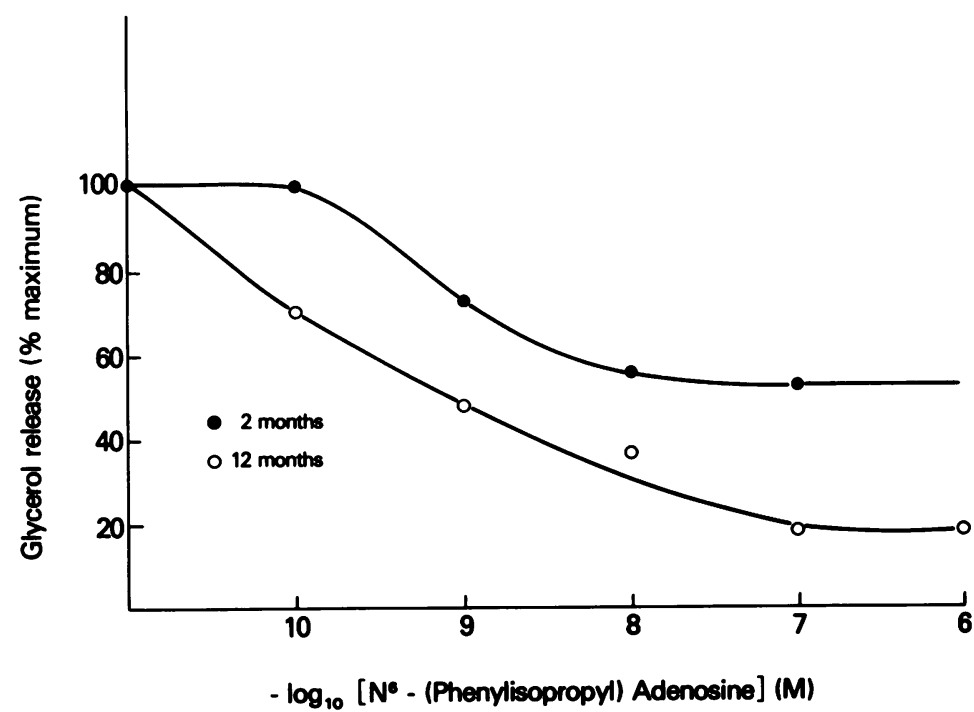

Figure 2. Inhibition of lipolysis by $N^{6}$-phenylisopropyladenosine. Fat cells were incubated in the presence of adenosine deaminase to abolish the effects of endogenously released adenosine. Lipolysis was stimulated with $10^{-7} \mathrm{M}$ isoproterenol. Inhibition is expressed as the percent inhibition of the stimulation seen with isoproterenol alone. This representative experiment was repeated six times. 
diates the inhibition of adenylate cyclase by these receptors $(16,17)$. Rats were injected with pertussis vaccine $(0.4 \mathrm{ml})$ and killed $3 \mathrm{~d}$ later. After treatment with pertussis vaccine, $N^{6}$-phenylisopropyladenosine, in the presence of adenosine deaminase, did not inhibit maximal isoproterenol-stimulated lipolysis in either the younger or older rats (Fig. 3). This indicated that the vaccine functionally inactivated the inhibitory adenosine receptors in both groups of rats. Consequently, endogenously released adenosine would be incapable of inhibiting lipolysis in these cells. Therefore, cells from these vaccinated rats were also exposed to $10^{-6} \mathrm{M}$ isoproterenol in the absence of added adenosine deaminase. This concentration of isoproterenol caused a maximal activation of lipolysis. As shown in Fig. 4, after treatment with pertussis vaccine, there was no significant difference in the ability of isoproterenol to stimulate lipolysis in the two groups. These data indicate that when the effect of endogenous adenosine is abolished by functionally inactivating adenosine receptors, lipolysis may be effectively activated by beta adrenegic stimulation in the cells from older rats.

To explore the mechanism for the enhanced inhibition of lipolysis by adenosine, we measured adenosine receptors in membranes from the two groups of rats with $N^{6}-\left[{ }^{3} \mathrm{H}\right]$ phenylisopropyladenosine. The results in Table II indicate that there was no difference in dissociation constant or adenosine receptor density, when expressed as femtomoles per milligram of protein. However, there are approximately twice as many adenosine receptors/cell in the older rats. This may reflect the larger cell size of adipocytes from older rats.

\section{Discussion}

In confirmation of others (4-7) and our earlier results (7a), we find that isoproterenol is less effective in activating lipolysis in adipocytes from older rats compared with younger rats. We

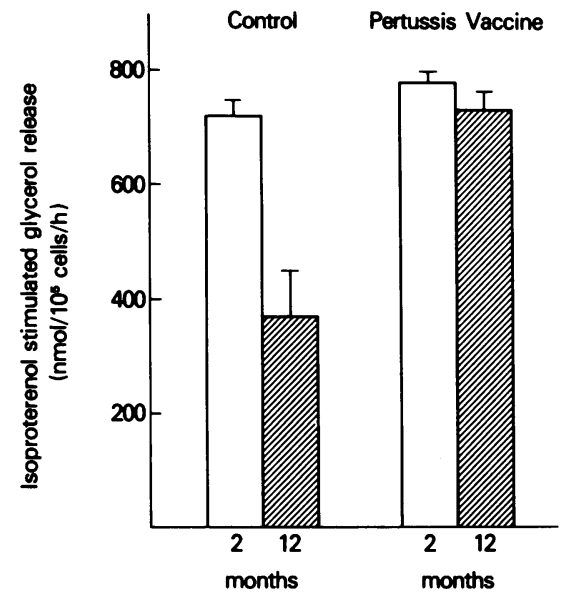

Figure 4. Stimulation of lipolysis by isoproterenol after pertussis vaccine. Rats were injected with pertussis vaccine and their isolated fat cells were shown to be unresponsive to $N^{6}$-phenylisopropyladenosine as indicated in the legend to Fig. 3. Isoproterenol $\left(10^{-6} \mathrm{M}\right)$ in the absence of added adenosine deaminase was used to stimulate lipolysis. The stimulation of lipolysis by isoproterenol was diminished in the uninjected 12-mo-old control rats as compared with uninjected 2 -mo control rats $(P<0.001)$. However, there was no significant difference in the ability of isoproterenol to activate lipolysis between 2 - and 12-mo-old rats that had been injected previously with pertussis toxin. The data represent the mean \pm SEM of seven experiments.

have previously demonstrated that the rate limiting deficit in these cells appears to be proximal to protein kinase activation, since lipolysis is equally well-activated by a cAMP analogue in the two groups (7a). Our present results suggest that the decrement in maximal isoproterenol-stimulated lipolysis seen in adipocytes from older rats occurs because endogenously released adenosine inhibits isoproterenol-induced lipolysis more effectively in the older rats.

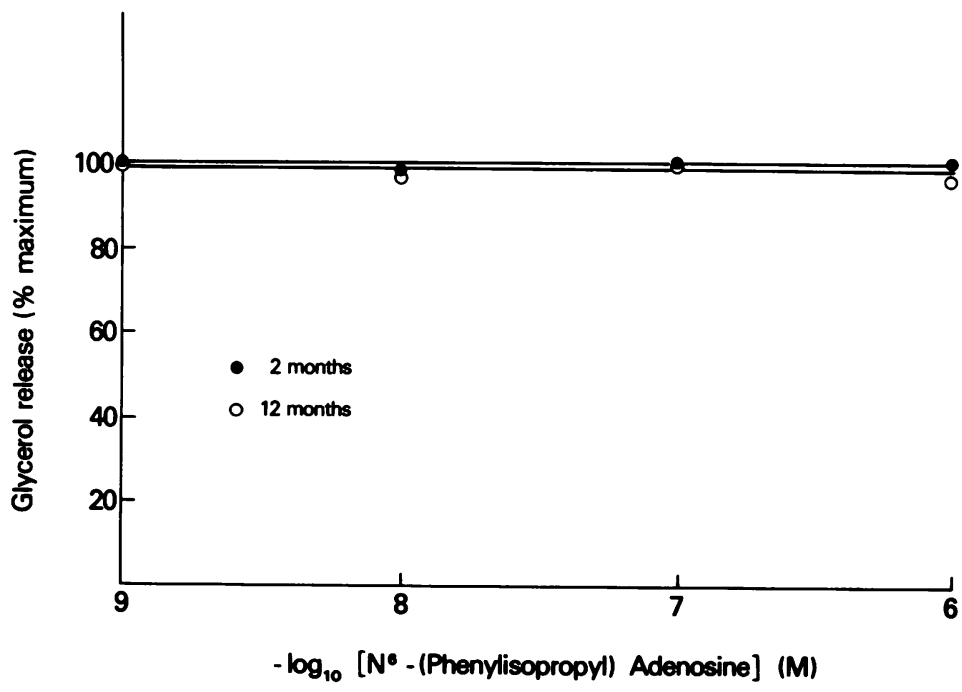

Figure 3. Abolishment of adenosine receptor mediated inhibition of lipolysis by pertussis vaccine. Rats in the two age groups were injected with $0.4 \mathrm{ml}$ of pertussis vaccine and killed $3 \mathrm{~d}$ later. $N^{6}$-phenylisopropyladenosine was not able to inhibit isoproterenol-stimulated lipolysis in the presence of adenosine deaminase in these cells. These data are the mean of six separate experiments. 
Table II. Adenosine Receptors in Adipocytes

\begin{tabular}{llll}
\hline & $\begin{array}{l}\text { Receptor } \\
\text { number }\end{array}$ & $\begin{array}{l}\text { Receptor } \\
\text { number }\end{array}$ & $K_{\mathrm{D}}$ \\
\hline & $f m o l / m g$ protein & sites/cell & $n M$ \\
2-mo-old rats & $529 \pm 58(n=6)$ & $24,541 \pm 3,254$ & $5.5 \pm 1.0$ \\
12-mo-old rats & $500 \pm 21(n=7)$ & $42,837 \pm 6,792^{*}$ & $5.2 \pm 0.9$ \\
& & & \\
\hline
\end{tabular}

${ }^{*} P<0.05$.

The evidence in favor of this hypothesis comes from several quite distinct experimental tests. The addition of adenosine deaminase normalized the response of the adipocytes from the older rats to isoproterenol. In the incubation media, adenosine deaminase effectively metabolizes adenosine to inosine. Isolated fat cells release sufficient adenosine as a dephosphorylation product of adenosine nucleotides to inhibit lipolysis via adenosine receptors (10). Because inosine is inactive in this regard, the normalized response of the adipocytes from the older rats to isoproterenol in the presence of adenosine deaminase suggests that adenosine was inhibiting lipolysis to a greater extent in the older group.

When the inhibitory effect of adenosine was removed with adenosine deaminase it was possible to stimulate directly the inhibitory adenosine receptors with $N^{6}$-phenylisopropyladenosine, an adenosine analogue that is not a substrate for adenosine deaminase. We found that the maximal inhibition of lipolysis with $N^{6}$-phenylisopropyladenosine was greater in the older group. This observation tends to confirm the hypothesis that adenosine-mediated inhibition of lipolysis is a major contributor to the blunted response to isoproterenol. We have not addressed the additional possibility that there is a difference in the amount of adenosine released by the two groups. The increased ability of $N^{6}$-phenylisopropyladenosine to inhibit lipolysis in the presence of adenosine deaminase indicates, however, that there is an important difference between the two groups that cannot be explained by possible differences in adenosine release.

The results with pertussis vaccine tend to support the conclusions drawn from the experiments with adenosine deaminase and $N^{6}$-phenylisopropyladenosine. Pertussis vaccine, which contains pertussis toxin in an impure form, inactivated the functional ability of adenosine receptors to inhibit lipolysis (Fig. 3). Under these conditions, maximal stimulation of lipolysis by isoproterenol was restored in the older group. Pertussis toxin catalyzes the ADP-ribosylation of a 41,000-D protein that apparently is a subunit of $\mathrm{Ni}$, the inhibitory guanine nucleotide regulatory protein $(16,17)$. This covalent modification of $\mathrm{Ni}$ is thought to be the explanation for the physiological effects of pertussis toxin. We have used an impure preparation that contains pertussis toxin; consequently other actions of the vaccine are possible. There was, however, no effect of the vaccine on maximal responsiveness in the younger group, suggesting that possible nonspecific effects of the vaccine on adipocyte responsiveness to isoproterenol are unlikely.

Blunted responsiveness of adipocytes to beta adrenergic agonists has been seen in a variety of settings. For example, beta adrenergic stimulation of lipolysis is diminished in fat cells from hypothyroid rats, lactating rats, and adrenalectomized rats. Interestingly, in each of these settings, there is evidence that adenosine mediated-inhibition of lipolysis may be accentuated (18-20). Consequently, there appear to be similarities between those situations and the age-related changes described here. The mechanism responsible for the enhanced efficacy of adenosine in inhibiting lipolysis in our studies is uncertain. There was no change in the number of adenosine receptors in the older group when expressed in femtomoles per milligram of protein. Whereas the number of the adenosine receptors per cell was increased in the older group, in view of the increase in cell size with aging, it is difficult to conclude that this change is of any biologic significance. To what extent alteration in activity of $\mathrm{Ni}$ may account for the findings remains an open question.

With age, the ability of many hormone receptors to activate adenylate cyclase has been found to decline (1). Much investigative effort has focused on these receptors and their coupling with stimulatory regulatory protein, Ns, and adenylate cyclase (1, 3, 21-23). Our studies indicate the importance of considering the possibility that enhanced inhibitory mechanisms may be responsible for the diminished action of stimulatory hormones. A wide variety of endogenous substances such as catecholamines, prostaglandins, and opiate peptides interact with receptors that inhibit adenylate cyclase activity and attenuate responses to stimulatory hormones. To what extent our observations in adipocytes will be generalizable to other tissues and hormones in explaining changes with aging remains an interesting question for further study.

\section{Acknowledgments}

Ms. Lelie VerBerkmoes provided expert secretarial assistance.

This work was supported by grants from the National Institute of Health GM 31206-02 and the Research Services of the Veterans Administration. Dr. Brian B. Hoffman is supported by a PMA Faculty Development Award and a Hartford Foundation Fellowship.

\section{References}

1. Roth, G. S. 1979. Hormone action during aging: alterations and mechanisms. Mech. Aging Dev. 9:497-514.

2. Fleisch, J. H. 1981. Age-related decrease in beta adrenoceptor activity of the cardiovascular system. Trends Pharmacol. Sci. 2:337339.

3. Abrass, I. B., J. L. Davis, and P. J. Scarpace. 1982. Isoproterenol responsiveness and myocardial beta adrenergic receptors in young and old rats. J. Gerontol. 37:156-160.

4. Form, J., P. S. Settonhoner, I. F. Skidmore, and G. Krishna. 
1970. Effect of aging on the adenylcyclase and phosphodiesterase activity of isolated fat cells of rat. Biochim. Biophys. Acta. 208:304309.

5. Nakano, J., A. C. Gin, and T. Ishii. 1971. Effect of age on norepinephrine-, ACTH-, theophylline- and dibutryl cyclic AMPinduced lipolysis in isolated rat fat cells. J. Gerontol. 26:8-12.

6. Guidicelli, Y., and R. Pecquery. 1978. Beta adrenergic receptors and catecholamine-sensitive adenylate cyclase in rat fat cell membranes: influence of growth, cell size and aging. Eur. J. Biochem. 90:413-419.

7. Dax, E. M., J. S. Partilla, and R. I. Gregerman. 1981. Mechanism of age-related decrease of epinephrine-stimulated lipolysis in isolatedrat adipocytes: beta-adrenergic receptor binding, adenylate cyclase activity and cyclic AMP accumulation. J. Lipid Res. 22:934-943.

7a. Hoffman, B. B., H. Chang, Z. T. Farahbakhsh, and G. M. Reaven. 1984. Age-related decrement in hormone stimulated lipolysis. Am. J. Physiol. In press.

9. Fain, J. N., and P. B. Wieser. 1975. Effects of adenosine deaminase on cyclic adenosine monophosphate accumulation, lipolysis and glucose metabolism of fat cells. J. Biol. Chem. 250:1027-1034.

10. Arch, J. R. S., and E. A. Newsholme. 1978. The control of the metabolism and the hormonal role of adenosine. Essays Biochem. 14:82-121.

11. Rodbell, M. 1964. Metabolism of isolated fat cells I. Effects of hormones on glucose metabolism and lipolysis. J. Biol. Chem. 239:375380 .

12. Wieland, O. 1964. Glycerol: UV Method. Methods Enzymatic Anal. 3:1404-1409.

13. Trost, T., and U. Schwabe. 1980. Adenosine receptors in fat cells: identification by $(-) \mathrm{N}^{6}-\left[{ }^{3} \mathrm{H}\right]$ phenylisopropyladenosine binding. Mol. Pharmacol. 19:228-235.

14. Yajima, M., K. Hosoda, Y. Kanbagashi, T. Nakamura, K. Nogimore, Y. Mizushima, Y. Nakase, and M. Ui. 1978. Islet-activating protein (IAP) in Bordetella pertussis that potentiates insulin secretory responses of rats. Purification and characterization. J. Biochem. 83:295303.

15. Moreno, F. J., I. Mills, J. A. Garcia-Sainz, and J. N. Fain. 1983. Effects of pertussis toxin treatment on the metabolism of rat adipocytes. J. Biol. Chem. 258:10938-10943.

16. Katada, K., and M. Ui. 1982. Direct modification of the membrane adenylate cyclase system by islet-activating protein due to ADP-ribosylation of a membrane protein. Proc. Natl. Acad. Sci. USA. 79:3129-3133.

17. Katada, T., and M. Ui. 1982. ADP ribosylation of the specific membrane protein of $\mathrm{C} 6$ cells by islet-activating protein associated with modification of adenylate cyclase activity. J. Biol. Chem. 257:72107216.

18. Ohisalo, J. J., and J. E. Stouffer. 1979. Adenosine, thyroid status and regulation of lipolysis. Biochem. J. 178:249-251.

19. Aitchison, R. E. D., R. A. Cleyg, and R. G. Vernon. 1982. Lipolysis in rat adipocytes during pregnancy and lactation: the response to noradrenaline. Biochem. J. 202:243-247.

20. Saggerson, E. D. 1980. Increased antilipolytic effect of the adenosine ' $\mathrm{R}$-site' agonist $\mathrm{N}^{6}$-(phenylisopropyl) adenosine in adipocyte from adrenalectomized rats. FEBS (Fed. Eur. Biochem. Soc.) Lett. 115:127-128.

21. O'Connor, S. W., P. J. Scarpace, and I. B. Abrass. 1981. Ageassociated decrease of adenylate cyclase activity in rat myocardium. Mech. Aging. Dev. 16:91-95.

22. Volicer, L., C. D. West, A. R. Chase, and L. Greene. 1983. Beta adrenergic receptor sensitivity in cultured vascular smooth muscle cells: effect of age and dietary restriction. Mech. Aging Dev. 21:283293.

23. Abrass, I. B., and P. J. Scarpace. Catalytic unit of adenylate cyclase: reduced activity in aged-human lymphocytes. J. Clin. Endocrinol. Metab. 55:1026-1028. 